\title{
Knowledge and attitude toward first aid: $A$ cross-sectional study in the United Arab Emirates
}

\author{
Omar Midani, Tala Tillawi, Ahmad Saqer, Mohammad Bakri Hammami, Hazem Taifour, Heba Mohammad \\ Departments of Basic and Clinical Sciences, College of Medicine, University of Sharjah, Sharjah, United Arab Emirates
}

\begin{tabular}{|c|}
\hline Access this article online \\
\hline Website: www.avicennajmed.com \\
\hline DOI: 10.4103/ajm.AJM_140_18 \\
\hline Quick Response Code: \\
\hline
\end{tabular}

\begin{abstract}
Background: Injury is an important cause of mortality and morbidity. It is the second most common cause of death in the United Arab Emirates (UAE) for the last 15 years, claiming more than 1200 lives annually. Those numbers can be significantly reduced through first aid (FA) education and training. The aim of this study was to investigate the knowledge and attitude toward FA in the UAE. Methods: Self-administered questionnaires were distributed through nonprobability sampling method to more than 500 residents across the UAE, aged at least 30 years. Data collection was conducted between July 20, 2017, and September 20, 2017. The number of participants from each city was proportionate to the population size according to the latest available census. Results: More than half of the population $(54.2 \%)$ were not sufficiently knowledgeable about basic FA. Only $33.8 \%$ took an FA course. Age of the participants, higher education, and taking FA courses significantly increased the knowledge about basic FA information. Most of the population showed positive attitude toward FA and were willing to take an FA course in the future. Conclusion: The knowledge about FA in the UAE population is limited. FA courses must be made more accessible for the population and updated at frequent intervals. More emphasis should be given to basic FA information.
\end{abstract}

Key words: Cross-sectional, first aid, knowledge, Middle East, public health

\section{INTRODUCTION}

Our modern society is increasingly exposed to a number of factors that put individuals in potentially dangerous situations. Accidents can happen equally at home or in the street. Road traffic accidents (RTA) are certainly the first example people think of when highlighting the benefits of first aid (FA). It is estimated that RTA kill more than 1.3 million people annually and injure as many as 78.2 million. ${ }^{[1]}$

FA is the immediate assistance provided to a suddenly injured or sick person until professional help arrives or that person has recovered. ${ }^{[2]}$ The sole purpose of FA is to preserve life, alleviate suffering, prevent further injury, and/ or promote recovery. ${ }^{[2,3]}$

Address for correspondence: Dr. Omar Midani, Departments of Clinical Sciences, College of Medicine,

University of Sharjah, Post Box No. 27272,

Sharjah, United Arab Emirates.

E-mail: omar.midani@hotmail.com
A considerable amount of time may pass before an ambulance arrives, but professional help can still be provided. FA has shown a significant decrease in mortality when applied in different situations. ${ }^{[4,5]}$ It is ascertained that properly administered FA (such as restoration of upper respiratory tract patency, pulmonary-circulatory resuscitation, applying pressure on a severed vessel, and placement of the victim in safe position) may save the lives of many victims of accidents; ${ }^{[6]}$ this makes it crucial to increase the knowledge about FA.

Education in FA should be universal and for all age groups including children in kindergarten. ${ }^{[7,8]}$ Such education can be accomplished through a variety of means including

This is an open access journal, and articles are distributed under the terms of the Creative Commons Attribution-NonCommercial-ShareAlike 4.0 License, which allows others to remix, tweak, and build upon the work non-commercially, as long as appropriate credit is given and the new creations are licensed under the identical terms.

For reprints contact: reprints@medknow.com

Cite this article as: Midani $\mathrm{O}$, Tillawi T, Saqer A, Hammami MB, Taifour $\mathrm{H}$, Mohammad $\mathrm{H}$. Knowledge and attitude toward first aid: A cross-sectional study in the United Arab Emirates. Avicenna J Med 2019;9:1-7. 
live classes, online courses, and public health campaigns. Compulsory training could help build communities that are less vulnerable and more resilient to the various risks to which they are exposed. Many developed countries adapted laws that obligate FA training either at schools, workplaces, or even when applying for a driving license. ${ }^{[9]}$

With the economic and technological development of the United Arab Emirates (UAE), injuries and accidents have also become a daily phenomenon. The four leading causes of death reported in the UAE are cardiovascular disease, injuries, cancer, and respiratory diseases. ${ }^{[10]}$ RTA constituted a major cause of premature death in the UAE among men below the age of 35 years, and such accidents also have been the cause of physical disability and long-lasting handicaps in an increasing number of people. ${ }^{[1]}$

The FA training is provided by many international organizations, health campaigns, and educational institutions throughout the UAE. However, the question that begs to be answered is: on a population level, what is the percentage of people that know the basics of FA and how to react in a life-threatening situation?

Unfortunately, there are few published reports assessing the general population's knowledge about FA in the Middle East. To the best of our knowledge, no such reports or studies have been conducted in the UAE. Hence, the purpose of this study was to assess the level of knowledge of UAE residents about different FA measures and to spot areas of deficiency. In addition, we aimed to quantify the degree of participation in FA courses and the willingness to offer FA measures for those in need.

\section{METHODS}

\section{Design of the study}

A descriptive, cross-sectional study was carried out in public malls, parks, and beaches accessible to the general population all over the UAE from July 20, 2017, to September 20,2017 . The main target population included adult UAE residents available at the time and place of data collection. Participants that did not match the criteria of the study were excluded. Exclusion criteria involved people who could not speak English or Arabic and those below the age of 30 years.

\section{Sample of the study}

Sample size was calculated based on the following formula: $n=4 p(1-p) * M E^{2}$, where $n$ is the sample size, ME the margin of error, and $p$ the expected prevalence, which was adapted from the studies carried out in neighboring countries as no previous studies were conducted in the
UAE. On the basis of that, the sample size was calculated to be 462 . Our study selected 500 participants by a convenient random sampling technique. Sample size from each city was calculated according to the population in each city based on the latest national census at the time of the study. ${ }^{[12]}$

\section{Tool of the study}

A self-administered anonymous questionnaire was constructed based on the previous surveys conducted elsewhere. ${ }^{[13,14]}$ The questionnaire was designed, pretested, and standardized following a pilot study that included a sample of 20 subjects.

The questionnaires consisted of three parts: (1) demographics, including age, gender, education level, and occupational status; (2) knowledge of basic FA information, including safety measures, emergency contact information, as well as basic steps performed before any FA procedure; and (3) knowledge of life-threatening situations to assess the responses of the population to different scenarios of injuries and accidents. Knowledge was assessed through multiple-choice questions. Pictures were used to show the correct maneuvers and positions for each scenario.

For each individual, a percentage of correct answers was calculated as a representative of an overall knowledge score. Knowledge was assessed in both broad and specific manner. A score of $67 \%$ and above was labeled as "good," between $33 \%$ and $67 \%$ was "moderate," whereas scores below 33\% indicated "poor" knowledge.

\section{Consent and ethical considerations}

Ethical approval for this study was obtained from the research ethics committee of the Medical Colleges, University of Sharjah, under the reference number REC-17-05-01-01. The questionnaire was carefully explained to all participants along with the aim and purpose of this study, and privacy was assured. Written informed consent was obtained individually, and those who did not sign the consent form were excluded from the study. All data along with consent forms were stored with the research investigators and treated with strict confidentiality.

\section{Data analysis}

Data analysis was performed using the Statistical Package for the Social Sciences (SPSS) software, version 23, (SPSS 23, IBM, Armonk, NY, United States of America). Descriptive statistics were used to describe the mean scores and proportions. To examine the correlation between knowledge and selected demographics and practices, Pearson's chi-square $\left(\chi^{2}\right)$ test and analysis of variance were used. All analyses were performed using two-tailed hypothesis testing with the level 
of significance set at 0.05 ( $P$ value). Results obtained were compared with other articles to evaluate and conclude.

\section{RESULTS}

\section{Demographics and basic information}

Of the 520 distributed questionnaires, 500 questionnaires were completed and matched the criteria with a response rate of $96.1 \%$. The sociodemographic characteristics of the sample matched the demographics of the population from the last national census at the time of the study. ${ }^{[12]}$ The sample consisted of 289 male (57.8\%) and 211 female $(42.2 \%)$ respondents. The mean participant age was $42.2(\mathrm{SD}=9.2)$ years. Most participants $(53.8 \%)$ were aged between 30 and 39 years, $27.2 \%$ were between 40 and 49 years, $12.6 \%$ were between 50 and 59 years, and $6.4 \%$ were above 60 years. When considering the medical background, which included doctors, physician assistants, and nurses, 69 (13.8\%) individuals had a medical background compared to $431(86.2 \%)$ that had none. Only 169 (33.8\%) individuals had taken an FA course compared to $331(66.2 \%)$ who had never received FA training. FA courses were mostly taken in schools
(32.7\%), universities (28.1\%), and private institutions $(18.1 \%)$.

Demographics of the sample in relation to their educational level are shown in Table 1.

\section{Knowledge about basic FA measures}

Knowledge scores of the population in relation to their demographics are summarized in Table 2 . When comparing the knowledge to age groups, the highest knowledge was found in individuals aged 60 years and older $(50.0 \%)$, whereas people in the age group of 30-39 years scored less in basic FA knowledge $(24.5 \%)$. A significant association was observed between age and basic FA knowledge level in our sample $\left(\chi^{2}=39.5, \mathrm{df}=12\right.$, $P<0.001)$. When comparing different educational levels, those with higher education had significantly higher knowledge scores in basic FA information than those with lower education $\left(\chi^{2}=39.9, \mathrm{df}=16, P=0.002\right)$. Gender, medical background, and taking FA courses did not significantly change the level of knowledge about basic FA information in our sample.

Basic FA questions and participants' responses are summarized in Table 3.

\begin{tabular}{|c|c|c|c|c|c|c|}
\hline Variables & & $\begin{array}{l}\text { Did not complete high } \\
\text { school }\end{array}$ & High school & Bachelor's degree & $\begin{array}{l}\text { Master's degree } \\
\text { and above }\end{array}$ & Total \\
\hline \multirow[t]{2}{*}{ Gender } & Male & $4(1.4 \%)$ & $80(27.7 \%)$ & 160 (55.4\%) & 45 (I5.6\%) & 289 \\
\hline & Female & $6(2.8 \%)$ & 92 (43.6\%) & 92 (43.6\%) & $21(10.0 \%)$ & 211 \\
\hline \multirow[t]{4}{*}{ Age group (years) } & $30-39$ & 7 (2.6\%) & $127(47.2 \%)$ & $116(43.1 \%)$ & 19 (7.1\%) & 269 \\
\hline & $40-49$ & $2(1.5 \%)$ & 30 (22.1\%) & 79 (58.1\%) & 25 (18.4\%) & 136 \\
\hline & $50-59$ & I (I.6\%) & $12(19.0 \%)$ & $38(60.3 \%)$ & $12(19.0 \%)$ & 63 \\
\hline & $60+$ & $0(0 \%)$ & $3(9.4 \%)$ & $19(59.4 \%)$ & $10(31.3 \%)$ & 32 \\
\hline \multirow[t]{2}{*}{ Medical background } & Medical & I (I.4\%) & 37 (53.6\%) & $26(37.7 \%)$ & $5(7.2 \%)$ & 69 \\
\hline & Nonmedical & $9(2.1 \%)$ & $135(31.3 \%)$ & $226(52.4 \%)$ & 61 (14.2\%) & 431 \\
\hline \multirow[t]{2}{*}{ Taken FA course } & Yes & $2(1.2 \%)$ & 49 (29.0\%) & 87 (5I.5\%) & 31 (18.3\%) & 171 \\
\hline & No & 8 (2.4\%) & $123(37.2 \%)$ & 165 (49.8\%) & 35 (10.6\%) & 331 \\
\hline
\end{tabular}

\begin{tabular}{|c|c|c|c|c|c|}
\hline Variable & Good knowledge & Moderate knowledge & Poor knowledge & Pearson's chi-square & $P$ value \\
\hline \multicolumn{6}{|l|}{ Age group (years) } \\
\hline $30-39$ & $66(24.5 \%)$ & $51(19.0 \%)$ & $152(56.5 \%)$ & \multirow[t]{4}{*}{$\chi^{2}=39.5, \mathrm{df}=12$} & \multirow[t]{4}{*}{$<0.001$} \\
\hline $40-49$ & 39 (28.7\%) & $18(13.2 \%)$ & 79 (58.1\%) & & \\
\hline $50-59$ & $28(44.4 \%)$ & $6(9.5 \%)$ & 29 (46.0\%) & & \\
\hline $60+$ & $16(50.0 \%)$ & $5(15.6 \%)$ & II (34.4\%) & & \\
\hline \multicolumn{6}{|l|}{ Educational level } \\
\hline Did not complete high school & $3(30.0 \%)$ & $3(30.0 \%)$ & $4(40.0 \%)$ & \multirow[t]{4}{*}{$\chi^{2}=39.9, \mathrm{df}=16$} & \multirow[t]{4}{*}{0.002} \\
\hline High school & $32(18.6 \%)$ & 33 (19.2\%) & 107 (62.2\%) & & \\
\hline Bachelor's degree & $93(36.9 \%)$ & $36(14.3 \%)$ & $123(48.8 \%)$ & & \\
\hline Master's degree or higher & $21(31.8 \%)$ & $8(12.1 \%)$ & $37(56.1 \%)$ & & \\
\hline \multicolumn{6}{|l|}{ Medical background } \\
\hline Medical & 14 (20.3\%) & $13(18.8 \%)$ & $42(60.9 \%)$ & \multirow[t]{2}{*}{$\chi^{2}=1.33, \mathrm{df}=4$} & \multirow[t]{2}{*}{0.857} \\
\hline Nonmedical & 135 (31.3\%) & $67(15.5 \%)$ & $229(53.1 \%)$ & & \\
\hline \multicolumn{6}{|l|}{ Taken the FA course } \\
\hline Yes & $45(26.6 \%)$ & $29(17.2 \%)$ & $95(56.2 \%)$ & \multirow[t]{3}{*}{$\chi^{2}=5.52, \mathrm{df}=4$} & \multirow[t]{3}{*}{0.238} \\
\hline No & $104(31.4 \%)$ & $51(15.4 \%)$ & $176(53.1 \%)$ & & \\
\hline Total & $149(29.8 \%)$ & $80(16 \%)$ & $27 \mid(54.2 \%)$ & & \\
\hline
\end{tabular}


Knowledge about response in life-threatening situations

When dealing with life-threatening situations, 403 $(80.6 \%)$ individuals knew how to deal with choking and $362(72.4 \%)$ individuals knew how to deal with bleeding emergencies, whereas only 198 and 150 (39.6\% and 30.0\%) individuals knew how to deal with electric shocks and loss of consciousness, respectively.

People who had taken the FA course had the highest correct responses in dealing with all the situations, such as loss of consciousness, electric shocks and burns, choking, and bleeding, giving a value of $50.0 \%[F(1,495)=41.9, P<0.001]$, $87.6 \%[F(1,496)=14.8, P<0.001], 87.6 \%[F(1,496)=5.7$, $P=0.017]$, and $79.3 \%[F(1,477)=6.1, P=0.014]$, respectively.

Responses of the participants to life-threatening situations are summarized in Tables 4 and 5.

\section{Attitude of the population toward FA}

When asked if they were willing to help in a real-life situation, $67 \%$ said they were willing to help, whereas $33 \%$ were not willing. However, the majority of the sample $(83.7 \%)$ were interested in taking FA courses in the future, whereas $16.3 \%$ were not interested.

\section{DISCUSSION}

\section{Knowledge about FA}

The mean knowledge score in the UAE population indicated that more than half of the population (54.2\%) had poor knowledge of basic FA. Similar findings were reported in Poland, ${ }^{[15]}$ Jordan, ${ }^{[16]}$ India, ${ }^{[17]}$ and Turkey. ${ }^{[18]}$ A significant difference was observed among the age groups; the older the participants, the greater their knowledge of FA. This was also reported in China where $57.3 \%$ of the elderly population had knowledge of FA. ${ }^{[19]}$ With regard to the level of education, basic knowledge of FA was significantly higher in the participants with bachelor's degree and higher. On the one hand, this finding shows the importance of incorporating basic FA teaching within the educational system in the UAE. On the other hand, this result points out the knowledge gap in younger individuals and those with no educational qualifications. As labor workers, who are mostly uneducated, and school kids are among the vulnerable groups for accidents requiring FA skills, this finding shows the huge importance of educating and targeting those groups to decrease the morbidity and mortality associated with life-threatening situations. ${ }^{[17]}$

\section{Importance of FA courses}

Only $33 \%$ of our sample received FA training during their life. This result was still higher than the populations in India $(11.2 \%)^{[17]}$ and Jordan $(29.2 \%)^{[16]}$ but lower than the population in Turkey (61\%). ${ }^{[20]}$ This minimal percentage should not be blamed entirely on the population as most of the participants (83\%) expressed interest in attending FA courses. However, the inconsistent availability of these courses along with the expensive registration fees are some of the hurdles people face when opting for FA training. Thus, it is the role of the government to encourage people's participation in such courses by providing cheaper and widely available courses throughout the country. ${ }^{[6]}$

In our study, we found a statistical significance between taking FA courses and better response to life-threatening situations. This finding is consistent with previous studies. ${ }^{[16,21,22]}$ This finding highlights the importance of taking FA courses and mandating them for supervisors in higher risk environments such as schools, sports fields, and industrial factories. ${ }^{[18]}$

When asked about the basic FA information, no significant difference was observed between those who took FA courses and those who did not. This shows that equal emphasis must be given when teaching people how to deal with lifethreatening situations along with teaching the basics of FA. Similarly, this finding was also reported in New Zealand among high school FA-trained teachers. ${ }^{[23]}$ The importance of knowing the basics is fundamental to performing correct

\begin{tabular}{lrr}
\hline Table 3: Participants' responses regarding knowledge of basic first aid knowledge & $\begin{array}{c}\text { Correct } \\
\text { answers }\end{array}$ & $\begin{array}{c}\text { Wrong } \\
\text { answers }\end{array}$ \\
\hline Question & $31 \%(n=155)$ & $69 \%(n=345)$ \\
\hline $\begin{array}{l}\text { What is the medical emergency response number in UAE? (998) } \\
\text { Which of the following are essential steps before attempting any FA maneuver? }\end{array}$ & $45 \%(n=225)$ & $53 \%(n=275)$ \\
Identify the location of the scene. (Yes) & $63 \%(n=315)$ & $37 \%(n=185)$ \\
Assess the scene for safety. (Yes) & $56 \%(n=280)$ & $44 \%(n=220)$ \\
Estimate the number of victims, and phone the emergency department. (Yes) & $28.8 \%(n=144)$ & $71.2 \%(n=356)$ \\
Put on personal protective equipment. (Yes) & $68.1 \%(n=338)$ & $32.4 \%(n=162)$ \\
How do you assess any person in need of FA? & $62.3 \%(n=309)$ & $38.2 \%(n=19 I)$ \\
Ask questions to help find out what is wrong. (Yes) & $56.5 \%(n=28 I)$ & $43.5 \%(n=219)$ \\
Watch and listen for difficulty in breathing. (Yes) & \\
Look head to toe for injuries, and check for medical alert jewelry. (Yes) &
\end{tabular}




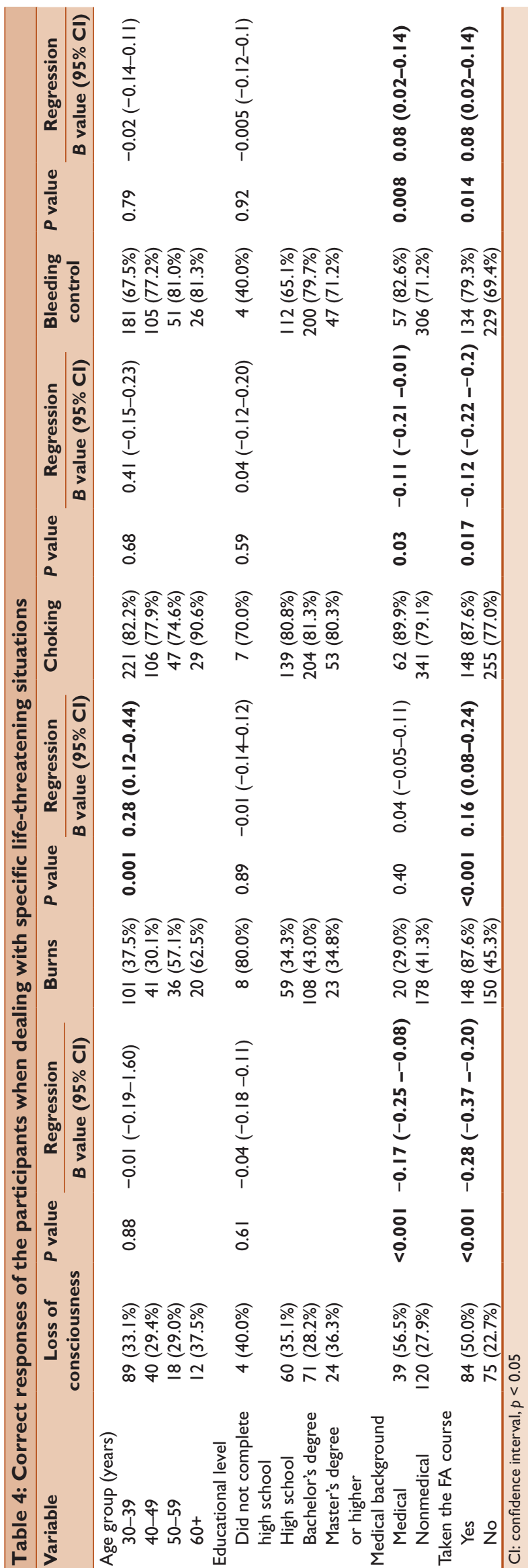

lifesaving practices when it comes to emergency situations. Thus, the revision of the FA course curriculum is encouraged to give higher importance to basic information. ${ }^{[24]}$

\section{FA and life-threatening situations}

Most of the participants in our sample were sufficiently knowledgeable about FA measures in cases of choking and bleeding emergencies. However, the knowledge about electric shocks and loss of consciousness was extremely low. Although no official statistics of electrical shocks in the UAE are available, a study in a nearby country (Iran) found that at least $2 \%$ of all burn cases are due to electrical shocks. ${ }^{[25]}$ Knowledge about the correct response in cases of electric shocks and loss of consciousness is vital to decrease the overall mortality and morbidity associated with these conditions.

Interestingly, $33 \%$ of our sample said they were not willing to help in case they were faced with a life-threatening situation. They attributed their response to the lack of confidence and expertise. Moreover, the participants said they feared the legal consequences associated with committing any mistake when dealing with such situations. It is worth mentioning that the UAE law prohibits any inexperienced involvement in accidents, fires, and criminal scenes.

\section{Methods to increase knowledge of FA}

The public needs to be more educated regarding FA and how to manage life-threatening situations. Communitybased interventions are vital and must be implemented. FA-trained participants received the course either in college or school. This signifies the importance of incorporating FA training within the educational system. Moreover, it is evident that taking the course alone is not enough to apply the knowledge in real-life situations. Implementation of knowledge tests before and after the course is encouraged to assess the benefit of the FA course on the participants. Follow-up courses are also encouraged every 6-12 months to ensure that the population remains well-informed and updated about the latest FA measures. ${ }^{[25]}$

It is mandatory for all health-care providers in the UAE to have a valid Basic Life Support certificate. However, this course must be also given to nonmedical individuals. Mandating the course for higher risk population is encouraged as a first step toward establishing a community program that targets the whole population. A mandatory course would significantly improve the knowledge and self-assessed skills of the participants. ${ }^{[24]}$

In addition, television advertisements can have an impact on the viewers' concepts of FA and can be used as a means 


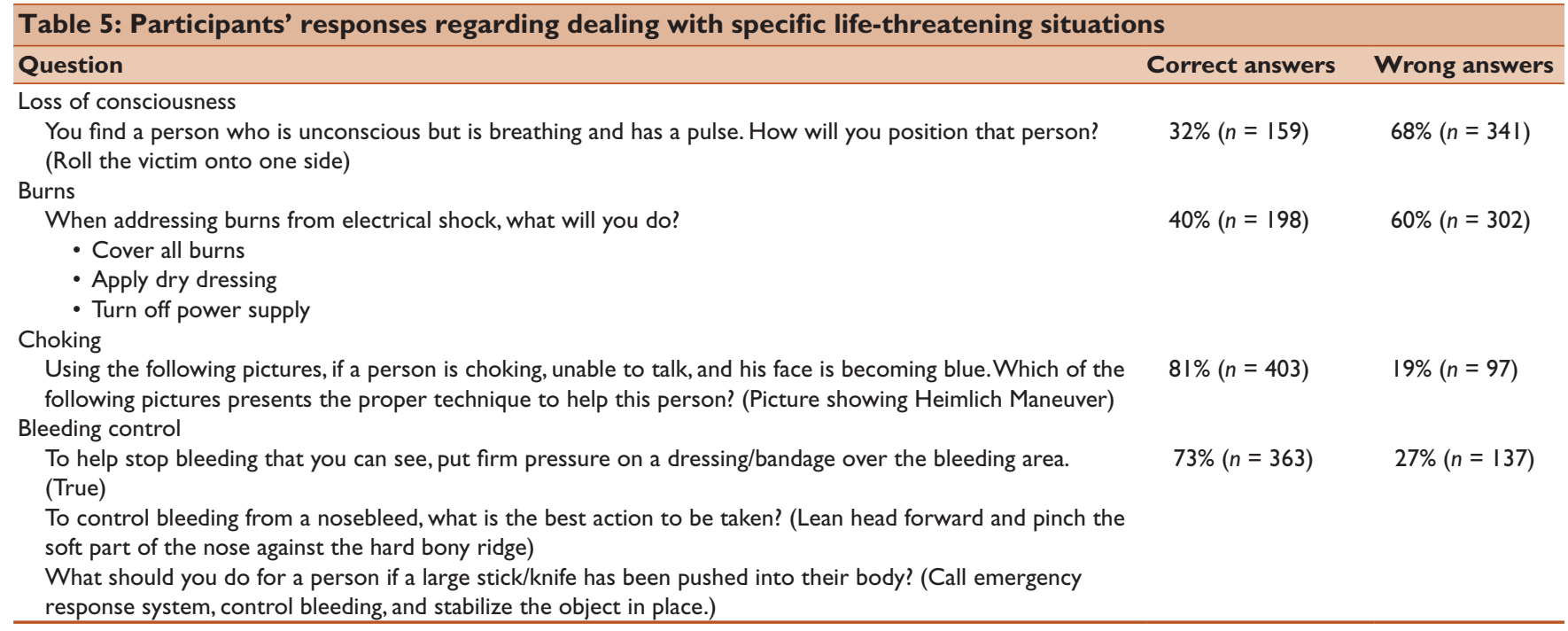

of increasing awareness and spreading knowledge. ${ }^{[26]}$ Increasing the knowledge of FA among the population would lead to knowledgeable individuals who are confident enough to deal with any critical situation that they would face. This could prove particularly vital to the country in the face of any natural disasters.

\section{CONCLUSION}

The population in the UAE is not sufficiently knowledgeable about FA. A low percentage of individuals have taken FA courses pertaining to the fact that those courses are taken voluntarily by individuals in the UAE. A large gap of knowledge was observed among the individuals who have not taken the courses regarding how to deal with life-threatening situations, which proves the importance of mandating the FA courses. Although the knowledge of life-threatening situations is important, it should not be overstressed at the expense of the basics of FA.

Future studies should investigate whether implementing a compulsory course would increase the knowledge of FA and the willingness of people to help. Moreover, the effect of teaching children the FA course should be investigated further. The time at which a FA course was taken might affect the results, which needs to be addressed. Finally, future investigations should look into the effect of different courses in dealing with real-life situations.

\section{Limitation of the study}

A convenient sampling method was used in this study, which decreases the generalizability of the results. However, this could not have been avoided as the UAE community is conservative, and thus, home visits for research would not have been welcomed. Our target population was individuals above the age of 30 years, which also leads to a decreased generalizability.

\section{Financial support and sponsorship}

Nil.

\section{Conflicts of interest}

All authors declare that there are no financial and personal relationships with other people or organizations that could have inappropriately influenced the work.

\section{REFERENCES}

1. Paniker J, Graham S, Harrison J. Global trauma: The great divide. SICOT-J 2015;1:19.

2. Van de Velde S, Heselmans A, Roex A, Vandekerckhove P, Ramaekers $D$, Aertgeerts B. Effectiveness of nonresuscitative first aid training in laypersons: A systematic review. Ann Emerg Med 2009;54:447-57, 457e1-5.

3. Pek J. Guidelines for Bystander First Aid 2016. Singapore Med J 2017;58:411-7.

4. Hoque D, Islam M, Sharmin Salam S, Rahman Q, Agrawal P, Rahman A, et al. Impact of first aid on treatment outcomes for non-fatal injuries in rural Bangladesh: Findings from an injury and demographic census. Int J Environ Res Public Health 2017;14:762.

5. The International Federation of Red Cross and Red Crescent Societies. First Aid for a Safer Future: Updated Global Edition. Advocacy Report 2010; 2010. Available from: http://www.ifrc.org/ PageFiles/53459/First $\% 20$ aid $\% 20$ for $\% 20$ a $\% 20$ safer $\% 20$ future $\% 20$ Updated\%20global\%20edition\%20\%20Advocacy $\% 20$ report $\% 202010 \% 20$ (2).pdf?epslanguage $=$ en. [Last accessed on 2018 Sep 1].

6. Mobarak A, Afifi R, Qulali A. First aid knowledge and attitude of secondary school students in Saudi Arabia. Health 2015;07:1366-78.

7. Bollig G, Myklebust A, Østringen K. Effects of first aid training in the kindergarten: A pilot study. ScandJ Trauma Resusc Emerg Med 2011;19:13.

8. Ammirati C, Gagnayre R, Amsallem C, Némitz B, Gignon M. Are schoolteachers able to teach first aid to children younger than 6 years? A comparative study. BMJ Open 2014;4:e005848.

9. Banfai B, Horvath N, Pandur A, Deutsch K, Radnai B, Csonka H, et al. First aid and resuscitation knowledge among laypeople with driving licence in Hungary. Resuscitation 2017;118:e65. 
10. Loney T, Aw T, Handysides D, Ali R, Blair I, Grivna M, et al. An analysis of the health status of the United Arab Emirates: The 'Big 4' public health issues. Global Health Action 2013;6:20100.

11. Koornneef E, Robben P, Blair I. Progress and outcomes of health systems reform in the United Arab Emirates: A systematic review. BMC Health Serv Res 2017;17:672.

12. Lopatin A. United Arab Emirates: Census. Federal Competitiveness and Statistics Authority Data Portal. Knoema; 2018. Available from: http:// datastat.fcsa.gov.ae/annkjob/united-arab-emirates-census. [Last accessed on 2018 Sep 1].

13. Hong Kong Red Cross Health and Care Service Department. Survey on Public Knowledge and Attitude on First Aid; 2011. Available from: https://www.redcross.org.hk/hcs_faht_files/news_events/ ExecutiveSummaryChartsEng.pdf. [Last accessed on 2018 Sep 1].

14. Alhejaili A, Alsubhi S. Knowledge and attitude of first aid skills among health science students at Taibah University. J Gen Practice 2016;4:257.

15. Sosada K, Zurawiński W, Stepień T, Makarska J, Myrcik D. [Evaluation of the knowledge of teachers and high school students in Silesia on the principles of first aid]. Wiad Lek 2002;55:883-9.

16. Khatatbeh M. First aid knowledge among university students in Jordan. Int J Prev Med 2016;7:24.

17. Joseph N, Kumar G, Nelliyanil M, Babu Y, Bhaskaran U. Knowledge of first aid skills among students of a medical college in Mangalore City of South India. Ann Med Health Sci Re 2014;4:162.
18. Başer M, Coban S, Taşci S, Sungur G, Bayat M. Evaluating first-aid knowledge and attitudes of a sample of Turkish primary school teachers. J Emerg Nurs 2007;33:428-32.

19. Sun W, Liu Y, Yan G, Meng W, Dong F. Research on present situation of pre-hospital first-aid knowledge of the elderly in community in Jilin. BIO Web Conf 2017;8:01010.

20. Bildik F, Kilicaslan I, Dogru C, Keles A, Demircan A. The need for first aid awareness among candidate teachers. TurkJ Emerg Med 2011;11:16670.

21. Metin CM, Mutlu C. Level of knowledge about first aid of the university students. Trakia J Sci 2010;8:262-5.

22. Hatzakis KD, Kritsotakis El, Angelaki HP, Tzanoudaki IK, Androulaki ZD. First aid knowledge among industry workers in Greece. Ind Health 2005;43:327-32.

23. Hooper R, Coggan C, Adams B. Injury prevention attitudes and awareness in New Zealand. Inj Prev 2003;9:42-7.

24. Adelborg K, Thim T, Secher N, Grove E, Løfgren B. Benefits and shortcomings of mandatory first aid and basic life support courses for learner drivers. Resuscitation 2011;82:614-7.

25. Arshi S, Sadeghi-Bazargani H, Mohammadi R, Ekman R, Hudson D, Djafarzadeh $\mathrm{H}$, et al. Prevention oriented epidemiologic study of accidental burns in rural areas of Ardabil, Iran. Burns 2006;32: 366-71.

26. Moeller B, Jeffers L. Technology for inclusive teaching. Electronic Learning 1996;16:44. 